\title{
A combined approach of hollow microneedles and nanocarriers for skin immunization with plasmid DNA encoding ovalbumin
}

This article was published in the following Dove Press journal:

International Journal of Nanomedicine

27 January 2017

Number of times this article has been viewed

\author{
Boonnada \\ Pamornpathomkul' \\ Adisak Wongkajornsilp ${ }^{2}$ \\ Wanida Laiwattanapaisal ${ }^{3}$ \\ Theerasak Rojanarata' \\ Praneet Opanasopit' \\ Tanasait Ngawhirunpat' \\ 'Department of Pharmaceutical \\ Technology, Faculty of Pharmacy, \\ Pharmaceutical Development of \\ Green Innovations Group, Silpakorn \\ University, Nakhon Pathom, \\ ${ }^{2}$ Department of Pharmacology, Faculty \\ of Medicine Siriraj Hospital, Mahidol \\ University, Bangkok, ${ }^{3}$ Department of \\ Clinical Chemistry, Faculty of Allied \\ Health Sciences, Chulalongkorn \\ University, Bangkok, Thailand
}

\begin{abstract}
The aim of this study was to investigate the use of different types of microneedles (MNs) and nanocarriers for in vitro skin permeation and in vivo immunization of plasmid DNA encoding ovalbumin (pOVA). In vitro skin permeation studies indicated that hollow MNs had a superior enhancing effect on skin permeation compared with solid MN patches, electroporation (EP) patches, the combination of MN and EP patches, and untreated skin. Upon using hollow MNs combined with nanocarriers for pOVA delivery, the skin permeation was higher than for the delivery of naked pOVA, as evidenced by the increased amount of pOVA in Franz diffusion cells and immunoglobulin $\mathrm{G}(\mathrm{IgG})$ antibody responses. When the hollow MNs were used for the delivery of nanocarrier:pOVA complexes into the skin of mice, they induced a stronger IgG immune response than conventional subcutaneous (SC) injections. In addition, immunization of mice with the hollow MNs did not induce signs of skin infection or pinpoint bleeding. Accordingly, the hollow MNs combined with a nanocarrier delivery system is a promising approach for delivering pOVA complexes to the skin for promoting successful immunization.
\end{abstract}

Keywords: hollow microneedle, solid microneedle, electroporation, plasmid DNA encoding ovalbumin, skin immunization, nanocarrier

\section{Introduction}

DNA vaccines are a novel technology for immunizations as an attractive alternative to conventional vaccines due to several advantages, including superior vaccine stability, ease of rapid and large-scale production, and the ability to induce potent cellular and humoral immune responses. ${ }^{1}$ DNA vaccines are plasmids containing a gene encoding an antigen and a promoter/terminator to induce the gene expression in mammalian cells, where it directs the synthesis of its polypeptide antigen. ${ }^{2}$ However, the use of DNA vaccines in the clinic is still limited because of their often poor immunogenicity. ${ }^{1,3,4}$ DNA vaccinations depend mainly on the delivery of plasmid DNA into cells to induce the expression of an encoded antigen. Therefore, the major reasons for their low level of immunity are the lack of suitable injection sites and the lack of proper delivery systems for DNA vaccines. ${ }^{5}$ Skin vaccinations have received attention as an alternate route of immunization. Skin layers are abundantly populated with professional antigenpresenting cells (APCs) within both the epidermis and the dermis, ie, Langerhans cells and dermal dendritic cells, respectively, which play important roles in effectively inducing immune responses. ${ }^{6,7}$ Thus, the delivery of DNA vaccines to skin layers can improve the immunogenicity. However, it is challenging to deliver high molecular weight molecules such as DNA vaccines into the skin because of the barrier effect
Correspondence: Tanasait Ngawhirunpat Faculty of Pharmacy, Pharmaceutical Development of Green Innovations Group, Silpakorn University, Nakhon Pathom 73000, Thailand

Tel +6634255800

Fax +663425580 I

Email ngawhirunpat_t@su.ac.th 
from the outermost stratum corneum layer of skin, ${ }^{8}$ and therefore, improved delivery strategies are necessary to overcome this challenge.

The conventional method of vaccination that involves subcutaneous (SC) injection using hypodermic needle has several limitations, including the induction of pain, the special training that is required, and the unsuccessful targeting of antigens of APCs. To avoid these limitations, various methods such as microneedles (MNs), ${ }^{9}$ electroporation (EP), ${ }^{10,11}$ gene guns, ${ }^{12}$ and jet injection ${ }^{13}$ have been investigated as efficacious DNA vaccination methods via the skin. Although the gene gun has received attention for DNA vaccination in the skin, it is limited by its expensive cost and Th2-biased immune response. ${ }^{13-15}$ Moreover, the use of multiple-use nozzle jet injectors leads to blood infections from cross-contamination of the injection nozzle and are no longer recommended for vaccinations. ${ }^{16}$ Therefore, in this study, physical enhancement methods were intentionally highlighted, including MNs and EP, to overcome the stratum corneum barrier and to improve the efficacy of gene therapy.

MNs have been considered as one of the most effective devices, as they can achieve painless skin penetration and are easy to use, easily scaled up, inexpensive, and reproducible via mass production. ${ }^{17}$ Thus, MNs are promising candidates for the delivery of DNA vaccines. MNs consist of micron-sized needles generally at lengths up to $1,000 \mu \mathrm{m},{ }^{18}$ and they can breach the stratum corneum to create holes for the passage of high molecular weight molecules through the skin barrier. In addition, $\mathrm{MN}$ holes are thought to be aqueous, thereby facilitating hydrophilic macromolecule ${ }^{19}$ and plasmid DNA transport. ${ }^{20}$ Four types of MNs have been used, including solid MNs (the poke and patch approach), coated MNs (the coat and poke approach), dissolving MNs (the poke and release approach), and hollow MNs (the poke and flow approach), each with their own advantages and disadvantages. ${ }^{18,20-22}$ Hollow MNs are an attractive approach as they can accurately deliver high dose of drug, and there is limited or no need to reformulate the vaccine. ${ }^{18}$

Recently, another physical method, EP, has also been shown to effectively deliver pDNA regardless of its electrical characteristics. It was discovered that EP can enhance the uptake of pDNA into the cells, resulting in an increase in protein antigen production ${ }^{23}$ and vaccine immunogenicity. ${ }^{24-26}$ EP is the application of high-voltage pulses within a very short time $(\mu \mathrm{s}-\mathrm{ms})$ to cause structural perturbation of lipid bilayer membranes. ${ }^{27}$ Additionally, the combination of $\mathrm{MN}$ patches and EP induced a synergistic effect on macromolecule skin permeation compared with MNs alone or conventional EP. ${ }^{28,29}$ However, until now, there has been a lack of publications on comparison of the effectivity of solid MN patches, EP patches, the combination of MN and EP patches, and hollow MNs for DNA vaccinations in skin both in vitro and in vivo.

In addition, genetic materials such as DNA vaccines are negatively charged and have a high molecular weight; thus, they require an effective carrier for enhanced delivery. However, it remains unknown whether delivery using the best device with different cationic nanocarriers for skin immunization with DNA is more effective than the delivery of naked pDNA alone. Therefore, in the present study, we examined the performance of several methods, including MN patches, the EP patches, the combination of MN and EP patches, and hollow MNs in an in vitro skin permeation study using a model plasmid antigen, plasmid DNA encoding ovalbumin (pOVA), without cationic nanocarriers, because it can express ovalbumin antigen to induce an immune response and has characteristically poor skin penetration. The best device was subsequently chosen for an in vitro skin permeation study and an in vivo immunization study in mice of pOVA complexes with different cationic nanocarriers, including polyethylenimine (PEI, cationic polymer), Lipofectamine 2000 (cationic lipid), and Superfect (cationic dendrimer).

\section{Materials and methods Materials}

Hollow MNs (Nanopass ${ }^{\mathrm{TM}}$; 33-gauge hypodermic needle, i.d., $0.20 \mathrm{~mm}$ ) were kindly provided by Terumo Co. (Tokyo, Japan). The acupuncture needle $(0.25 \times 30 \mathrm{~mm})$ was obtained from DongBang Acupuncture Inc. (Chung Nam, Korea). pOVA was a gift from Shoshana Levy (Addgene plasmid \#31598). Large-scale plasmid preparation was performed using QIAGEN ${ }^{\circledR}$ Plasmid Midi Kits Valencia (Qiagen, CA, USA). Branched PEI (MW 25,000) was purchased from Aldrich (Milwaukee, WI, USA). Lipofectamine 2000 was purchased from Invitrogen (Carlsbad, CA, USA). Superfect was obtained from Qiagen. Quant-iT ${ }^{\text {TM }}$ PicoGreen ${ }^{\circledR}$ dsDNA reagent and kits were purchased from Molecular Probes, Inc. (Eugene, OR, USA). Monoclonal anti-chicken egg albumin (OVA) antibody produced in mouse and rabbit anti-goat immunoglobulin $\mathrm{G}(\mathrm{IgG})$ peroxidase conjugate were purchased from Sigma-Aldrich (St Louis, MO, USA). 3,3',5,5'-Tetramethylbenzidine (TMB) was purchased from Zymed (San Francisco, CA, USA). Tween 20 and sulfuric acid $\left(\mathrm{H}_{2} \mathrm{SO}_{4}, 98 \% \mathrm{w} / \mathrm{w}\right)$ were supplied by BDH (Poole, Dorset, England). HeLa cells, the human cervical cancer cell 
lines, were purchased from American Type Culture Collection (ATCC, Maryland, USA). Fetal bovine serum (FBS), minimum essential media (MEM), L-glutamine, and MEM non-essential amino acids $(100 \times)$ were obtained from GibcoInvitrogen (New York, NY, USA). The goat anti-mouse IgG horseradish peroxidase (HRP) conjugate was $\mathrm{ZyMax}^{\mathrm{TM}}$ Grade. Sodium bicarbonate $\left(\mathrm{NaHCO}_{3}\right)$ was purchased from Fisher Scientific (Leicestershire, England). High-sensitive enzyme-linked immunosorbent assay (ELISA) kits for ovalbumin were purchased from Biomatik (Ontario, Canada). All other chemicals were of molecular biology quality.

\section{$\mathrm{MN}$ patch fabrication}

To prepare the $\mathrm{MN}$ patches, 32-gauge stainless steel needles $(0.25 \times 30 \mathrm{~mm})$ and a silicone sheet $(15 \times 15 \times 2 \mathrm{~mm})$ were employed. The silicone sheet was vertically punctured by the cut needles. The tips of the acupuncture needles extended $\sim 900 \mu \mathrm{m}$ out of the silicone sheet. The other end of the acupuncture needle was bent to anchor the acupuncture needle in the silicone sheet. These MNs were positioned in a $5 \times 5$ pattern ( 25 needles). The needles were then fixed to the silicon sheet with an adhesive tape as shown in Figure 1A. To ensure the length of needles, MN patches were observed under stereo zoom microscopes (SMZ-171 series; Motic ${ }^{\circledR}$, Hong Kong, China).

\section{$\mathrm{MN}+\mathrm{EP}$ patch and EP patch fabrication}

To examine the combinatorial effect of the MNs and EPs, the needles were prepared as described earlier. However, the copper wires, ie, the positive and negative lines, were inserted under the perpendicular part of the needle before fixing the needles with the silicone sheet so that the MN+EP

A
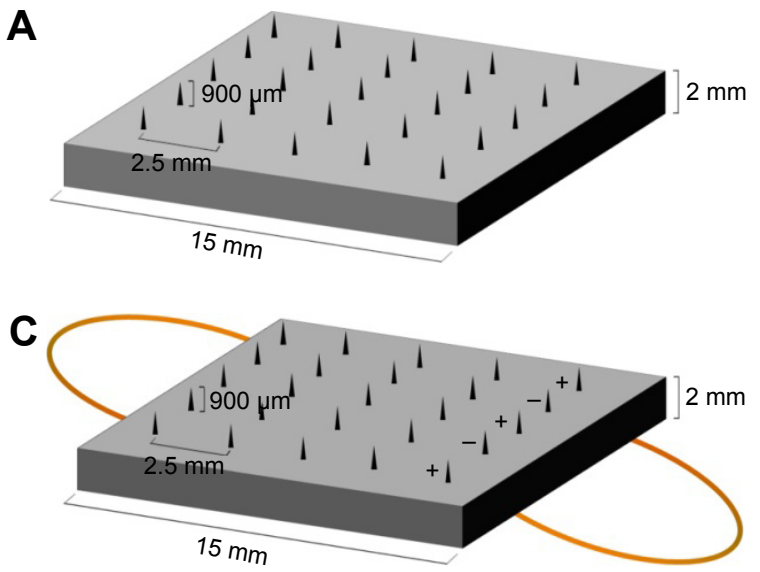

array could be used as an electrode in the EP experiments (Figure 1B and C). To investigate the effect of EPs alone and to eliminate the effect of the MN array, the tip of the needle was cut and filed until dull; these needles are referred to as blunted MNs (Figure 1B) and were used to prepare the blunted MN arrays following a method similar to that used to prepare the $\mathrm{MN}+\mathrm{EP}$ patches.

\section{Hollow MN preparation}

A 33-gauge hypodermic needle (Nanopass ${ }^{\mathrm{TM}}$; i.d., $0.20 \mathrm{~mm}$; Terumo Co.) was connected to a $100 \mu \mathrm{L}$ Hamilton syringe through a 27-gauge hypodermic needle (i.d., $0.22 \mathrm{~mm}$; o.d., $0.40 \mathrm{~mm}$; Terumo Co.) for intradermal injection. To maintain the insertion depth, the needle was fixed at a $40^{\circ}$ angle on a triangular silicone sheet to maintain a constant insertion depth of $\sim 300 \mu \mathrm{m}$ into the skin layer (Figure 1D).

\section{Preparation of pOVA}

The pOVAs were amplified from previously transformed stocks of Escherichia coli DH5 $\alpha$ using antibiotic-selective conditions. After amplification of the E. coli, the plasmids were isolated and purified by using QIAGEN Plasmid Maxi Kits. The quality and quantity of the purified pOVA were evaluated by the optical density at 260 and $280 \mathrm{~nm}$.

\section{Preparation of cationic nanocarrier:pOVA complexes}

The pOVA was mixed with different cationic nanocarriers at various weight ratios $(\mathrm{w} / \mathrm{w})$. The PEI:pOVA complex was prepared by adding the solution of branched PEI $(25 \mathrm{kDa})$ to the pOVA at different weight ratios of $0.25,0.5,1,2$, and 3 . For Lipofectamine 2000:pOVA, lipoplexes were prepared

B

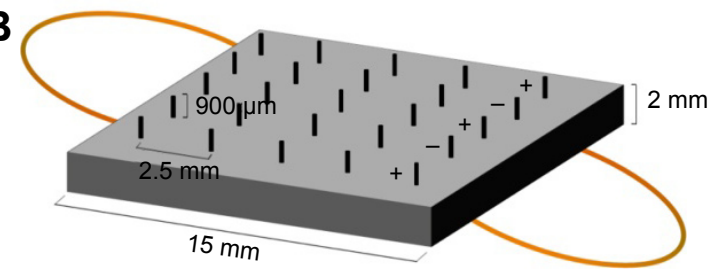

D

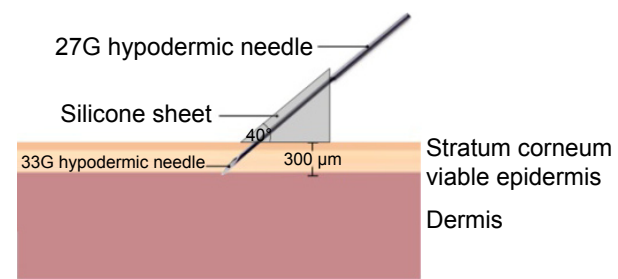

Figure I Schematic representation of $(\mathbf{A})$ a solid MN patch, $(\mathbf{B})$ an EP patch, (C) the combined solid MN and EP patch, and (D) a hollow MN inserted into the skin with a 33-gauge hypodermic needle.

Abbreviations: MN, microneedle; EP, electroporation. 
at weight ratios of 1, 2, 3, 4, and 5. Superfect:pOVA was prepared at weight ratios of 2, 3, 4, 6, and 15. Complexes were prepared according to the manufacturer's instructions. The mixtures were combined, gently mixed, and further incubated at room temperature for the appropriate time to initiate the formation of complexes.

\section{Characterization of cationic nanocarrier:pOVA complexes}

\section{Particle size and zeta potential analysis}

The particle size and surface charge of the cationic carrier/ pOVA complexes were determined by photon correlation spectroscopy using a Zetasizer Nano ZS. The amount of pOVA was fixed at $2 \mu \mathrm{g}$. The complexes were diluted with sterile water to $1 \mathrm{~mL}$ at the time of measurement. The measurement of each sample was performed in triplicate at $25^{\circ} \mathrm{C}, \mathrm{pH} 7.4$.

\section{Agarose gel retardation}

The cationic nanocarrier:pOVA complexes were prepared using $0.25 \mu \mathrm{g}$ pDNA with different nanocarriers at various weight ratios as described earlier. Agarose gel electrophoresis was performed using 1\% agarose in $1 \times$ Trisacetate-EDTA (TAE) buffer. The complex solutions were mixed with $50 \%$ glycerol before loading into the gel. Electrophoresis was carried out in TBE running buffer, $\mathrm{pH} 8.3$, for $45 \mathrm{~min}$ at $100 \mathrm{~V}$. The pOVA on agarose gel was then stained with ethidium bromide and destained in sterile water. The pOVA bands were visualized and photographed by a ultraviolet (UV) transilluminator using a GelDoc system.

\section{In vitro transfection efficiency}

Transfection study of cationic nanocarrier:pOVA complexes was performed in human cervical carcinoma cell (HeLa cells) lines. Briefly, HeLa cells were seeded in 48-well plates $\left(1 \times 10^{5}\right.$ cells/well $)$ and incubated at $37^{\circ} \mathrm{C}$ with $5 \% \mathrm{CO}_{2}$ for $24 \mathrm{~h}$. The cells were then transfected with cationic nanocarrier:pOVA complexes at different weight ratios in serum-free medium, the complexes containing $0.5 \mu \mathrm{g} /$ well of pOVA. After $4 \mathrm{~h}$, the transfection medium was replaced with fresh medium, and the cells were incubated overnight. The medium was collected, and the cells were trypsinized with a cell lysis buffer ( $50 \mathrm{mM}$ Tris, $150 \mathrm{mM} \mathrm{NaCl}, 1 \mathrm{mM}$ EDTA, and 1\% Triton X-100) and then frozen and thawed for 3 cycles. Insoluble materials were removed by centrifugation $\left(14,000 \mathrm{rpm}, 4^{\circ} \mathrm{C}, 10 \mathrm{~min}\right)$, and then the supernatant was collected. The total protein concentrations were measured both in the medium and the supernatant from the lysis of cells using a high-sensitive ELISA kit for OVA.

\section{Cytotoxicity of cationic nanocarrier:pOVA complexes}

The cytotoxicity of cationic nanocarrier:pOVA complexes was investigated using an MTT assay. HeLa cells were seeded into a $96-w e l l$ plate at a density of 8,000 cells/well and incubated at $37^{\circ} \mathrm{C}$ with $5 \% \mathrm{CO}_{2}$ for $24 \mathrm{~h}$ prior to transfection. The cells were then treated with the different nanocarrier:pOVA complexes under the same conditions and the weight ratios as in vitro transfection experiment. After $4 \mathrm{~h}$ of transfection, the media were removed, and the cells were then washed with phosphate-buffered saline (PBS) and continually incubated in the complete media for $24 \mathrm{~h}$. MTT solution (5 $\mathrm{mg} / \mathrm{mL}$ in PBS) was added to give the final concentration of $1 \mathrm{mg} / \mathrm{mL}$ to each well and incubated in normal conditions for $4 \mathrm{~h}$. The media were then removed, and the formazan crystals formed in the living cells were dissolved in $100 \mu \mathrm{L}$ per well of dimethyl sulfoxide (DMSO). The optical density was measured at $550 \mathrm{~nm}$ using a microplate reader (Universal Microplate Analyzer, Model AOPUS01 and AI53601; Packard BioScience, Connecticut, CT, USA). Relative viability (\%) was calculated according to Equation 1.

$$
\text { Relative viability }(\%)=\frac{\mathrm{OD}_{\text {treated cells }}}{\mathrm{OD}_{\text {non-treated cells }}} \times 100
$$

The viability of non-treated cells is defined as $100 \%$.

\section{Effect of serum on transfection efficiency}

To evaluate the stability against nuclease digestion, serum stability of pDNA in nanocarrier/pDNA complexes was determined as previously described. ${ }^{30}$ Our previous study found that pDNA without cationic nanocarriers was completely degraded in the presence of $10 \%$ serum for $6 \mathrm{~h} .{ }^{31}$ Therefore, the different cationic nanocarrier:pOVA complexes were incubated with $10 \%$ serum from female BALB/c mice (6-8 weeks old) for $6 \mathrm{~h}$ and analyzed on agarose gel electrophoresis. Different cationic nanocarrier:pOVA complexes $(0.25 \mu \mathrm{g}$ of pOVA) at the selected weight ratios were incubated with $10 \%$ serum at $37^{\circ} \mathrm{C}$ for $6 \mathrm{~h}$. In case of the samples containing the nanocarriers, $10 \%$ sodium dodecyl sulfate solution was added to the samples to extract pOVA from the nanocarriers, and the mixture was incubated at room temperature for $30 \mathrm{~min}$. All samples were loaded into 1\% agarose gel. The electrophoresis was performed for $45 \mathrm{~min}$ at $100 \mathrm{~V}$. The pOVA bands were visualized under a UV transilluminator using a GelDoc system. Naked pOVAs with and without serum were tested under the same conditions as control. 


\section{In vitro skin permeation studies}

Preparation of Sprague Dawley rat skin

Sprague Dawley rats (females, 5-6 weeks of age) were purchased from the National Laboratory Animal Center, Mahidol University, Thailand. This study was approved by the ethics committee for the use of laboratory animals, Faculty of Pharmacy, Silpakorn University (approval number: 002/2015). The experiments were conducted in accordance with the Animals for Scientific Purposes Act, 2015, provided by the Animal Care and Use Committee of National Research Council of Thailand. The hairs on the backs of the mice were shaved with electric clippers. Afterward, the upper part of the full-thickness skin was carefully excised from the dorsal region of the rats under anesthesia with intraperitoneal injection of sodium pentobarbital $(100 \mathrm{mg} / \mathrm{kg})$. The fat layer of the skin was carefully removed. The prepared skins were washed with PBS (pH 7.4), wrapped in aluminum foil, stored at $-20^{\circ} \mathrm{C}$, and thawed immediately prior to use.

\section{Assessment of Sprague Dawley rat skin integrity}

The integrity of skin samples of Sprague Dawley rat was checked by an electrical resistance method, in which the voltage across the rat skin was measured using a multimeter (Fluke 177; Fluke Corporation, Everett, WA, USA) with $\mathrm{Ag}$ and $\mathrm{Ag} / \mathrm{AgCl}$ electrodes when a small electric current $(<80 \mu \mathrm{A})$ was applied across the membrane. The skin electrical resistance was then calculated using the voltage and current readings. The selection criterion of skin samples with intact barrier function was skin electrical resistance $\geq 3 \mathrm{k} \Omega .^{32}$

\section{Skin permeation studies}

In vitro permeation studies of pOVA were performed using a vertical Franz diffusion cell. The Sprague Dawley rat skin samples were mounted on vertical Franz diffusion cells, with the epidermis side facing the donor compartment and the dermal side facing the receiver compartment; the apparatus was then affixed using clamps. The receiver compartment was filled with $6 \mathrm{~mL}$ PBS and stirred at $400 \mathrm{rpm}$ using a magnetic stirrer. The temperature was maintained at $32^{\circ} \mathrm{C} \pm 1{ }^{\circ} \mathrm{C}$ using a circulating water jacket. The studies were carried out for $24 \mathrm{~h}$ under occlusive conditions to avoid evaporation. To investigate the cumulative permeation profiles, a $500 \mu \mathrm{L}$ aliquot was withdrawn from the receptor at the time intervals of $0.5,1,2,4,6,8$, and $24 \mathrm{~h}$, followed immediately by replacement with equal volumes of fresh PBS to maintain a constant volume. Untreated skin samples with and without pOVA were used as controls.

\section{Skin permeation of different delivery devices}

To evaluate the effect of the MN patches, the EP patches, and the combination of $\mathrm{MN}$ and EP patches, $1 \mathrm{~mL}$ pOVA $(50 \mu \mathrm{g} / \mathrm{mL})$ without cationic nanocarriers were added to the donor compartment. In skin permeation experiments using the hollow MNs, the pOVA solutions alone were directly injected into the skin with the same concentration of pOVA. The experiments were performed in 5 parallel groups: 1) passive delivery, 2) $\mathrm{MN}$ patches alone, 3) EP patches alone, 4) MN+EP patches, and 5) hollow MN.

For the skin permeation experiments using the MN patch, the skin was pierced using the $\mathrm{MN}$ patch. A plastic container weighing $10 \mathrm{~N}$ was placed on the MN patch and left on the skin for 2 min. ${ }^{29,33}$ For the skin permeation experiments using the EP patch, EP was applied using a square-wave pulse generator (ECM 830 Electro Cell Manipulator; BTX, San Diego, CA, USA). The EP patch consisting of 25 blunted acupuncture needles connected with copper wire was used as an electrode to eliminate the effect of the needle. The skins were pre-treated with the EP patch at a pulse voltage of $150 \mathrm{~V}$. The pulse duration and number of pulses were fixed at $1 \mathrm{~ms}$ and 99 pulses, respectively.

The skin permeation experiments using the combination of the MN and EP patch: a patch composed of 25 acupuncture needles connected with copper wire was used as an electrode. The skin was punctured using the MN+EP patch with a force of $10 \mathrm{~N}$ for $2 \mathrm{~min}$. Pulse voltages at $150 \mathrm{~V}$ were transferred to the skin using a pulse generator via conditions similar to those described earlier.

For the skin permeation experiments using the hollow $\mathrm{MN}, 100 \mu \mathrm{L}$ of pOVA solution was injected directly into the skin with 10 injections per skin sample and manually delivered by applying gentle finger pressure to the syringe plunger.

\section{Skin permeation of POVA with cationic nanocarriers}

To study the effect of cationic nanocarriers on skin permeation, hollow MNs were chose to deliver cationic nanocarrier:pOVA complexes into the skin using the best device. The effects of various cationic nanocarriers were investigated, including PEI:pOVA at the weight ratio $(\mathrm{w} / \mathrm{w})$ of 1:1, Lipofectamine 2000:pOVA at a ratio of $2: 1$, and Superfect:pOVA at a ratio of $6: 1$, as these weight ratios provided the highest transfection efficiency in the HeLa cells. The pOVA complexes with different cationic nanocarriers were injected directly into the skin. The volume of solution applied was kept constant at $100 \mu \mathrm{L}$ with 10 injections per skin sample. 


\section{Quantitative assay}

The amount of pOVA diffused into the receiver compartment was quantified via a Quant-i ${ }^{\mathrm{TM}}$ PicoGreen assay and Fluoroskan Ascent ${ }^{\mathrm{TM}}$ Microplate Fluorometer (Thermo Fisher Scientific, MA, USA) with an excitation wavelength of $480 \mathrm{~nm}$ and an emission wavelength of $520 \mathrm{~nm}$. In case of the samples containing the nanocarriers, $10 \%$ sodium dodecyl sulfate solution was added to the samples to extract pOVA from the nanocarriers, and the mixture was incubated at room temperature for $30 \mathrm{~min}$ before being stained with a Quant-iT ${ }^{\mathrm{TM}}$ PicoGreen. As a control, the permeation of pOVA through intact skin at various time intervals $(0.5,1,2$, $4,6,8,12$, and $24 \mathrm{~h}$ ) was also evaluated. The concentrations were calculated using a calibration curve.

\section{Immunization study}

Female BALB/c mice, 6-8 weeks at the start of the experiment, were obtained from the National Laboratory Animal Center, Mahidol University, Thailand. The mice $(n=6$ animals per group) were housed in a temperature-controlled room $\left(25^{\circ} \mathrm{C} \pm 2^{\circ} \mathrm{C}\right)$ in a 12 -h light-dark cycle. Mice were provided free access to food and water. The mice were divided into 10 groups; naïve group received sterile normal saline as a negative control, and the other groups were immunized with different pOVA formulations and routes as described in Table 1. The mice in all groups were immunized on days 0 and 14 .

For the hollow MN immunization, the mice were anesthetized by intraperitoneal injection with sodium pentobarbital (40 mg/kg). The dorsal sides of the mice were shaved using electric clippers followed by an electric razor. The shaved skin was gently swabbed with $70 \%$ ethanol and allowed to dry. The mice were immunized 2 times with $100 \mu \mathrm{L}$ of different pOVA formulations $(100 \mu \mathrm{g} / \mathrm{mL}$ of pOVA) into the superficial dermal layer with hollow MNs fixed at a $40^{\circ}$ angle, as described earlier. The safety of the mice was evaluated by assessing the mouse skin sites for signs of skin bleeding and infection. ${ }^{34}$

For the SC immunization, conscious mice were immunized subcutaneously in the neck region.

\section{Sample collection}

On day 0 , blood samples $(0.2 \mathrm{~mL}$ per animal $)$ were collected from the cut tail tip. At the end of the study (day 21), blood (0.6-1 mL per animal) collection was performed by cardiac puncture following anesthesia of the mice with diethyl ether. The blood samples were left to clot overnight and were then centrifuged at $8,000 \times g$ for $5 \mathrm{~min}$ at $4^{\circ} \mathrm{C}$. For tail bleeds, the serum was collected and pooled for each group of mice. The serum collected via cardiac puncture from each mouse was stored separately. All serum samples were stored at $-20^{\circ} \mathrm{C}$ until assayed.

\section{Determination of serum antibody responses}

The levels of OVA-specific serum IgG antibody were analyzed according to the standard ELISA protocol. Briefly, 96-well microtiter plates were coated with $50 \mu \mathrm{L}$ of $100 \mu \mathrm{g} / \mathrm{mL}$ OVA in coating solution (0.1 $\left.\mathrm{M} \mathrm{NaHCO}_{3}, \mathrm{pH} 8.2\right)$ at $4{ }^{\circ} \mathrm{C}$ overnight. The plates were then washed 3 times with $0.05 \%(\mathrm{v} / \mathrm{v})$ Tween 20 in PBS (T20/PBS) and blocked with $200 \mu \mathrm{L}$ of $10 \%(\mathrm{v} / \mathrm{v}) \mathrm{FBS}$ in PBS (10 FBS/PBS) for $2 \mathrm{~h}$ incubation at room temperature. After washing 6 times with T20/PBS, the plates were incubated with $200 \mu \mathrm{L}$ serially diluted serum samples in $10 \mathrm{FBS} / \mathrm{PBS}$ for $1 \mathrm{~h}$. For the standard curve, an OVA-specific monoclonal antibody at a concentration of $100 \mathrm{ng} / \mathrm{mL}$ was diluted with $10 \mathrm{FBS} / \mathrm{PBS}$ in the ELISA plates, resulting in a series of concentrations ranging from 100 to $1.56 \mathrm{ng} / \mathrm{mL}$. The plate was then washed

Table I Immunization of pOVA in each mice group $(n=6)$

\begin{tabular}{|c|c|c|}
\hline Mice groups & Formulations & $\begin{array}{l}\text { Route of } \\
\text { administrations }\end{array}$ \\
\hline Naïve I & I00 $\mu \mathrm{L}$ sterile normal saline & SC \\
\hline Naïve 2 & I $00 \mu \mathrm{L}$ sterile normal saline & Hollow MN \\
\hline SC I & $10 \mu g$ of pOVA in PBS, $\mathrm{pH} 7.4$ & $\mathrm{SC}$ \\
\hline SC 2 & PEI: $10 \mu g$ of pOVA $(\mathrm{I}: \mathrm{l})$ in PBS, $\mathrm{pH} 7.4$ & SC \\
\hline SC 3 & Lipofectamine 2000: $10 \mu \mathrm{g}$ of pOVA (2:I) & SC \\
\hline SC 4 & Superfect: $10 \mu g$ of pOVA (6:I) in PBS, $\mathrm{pH} 7.4$ & SC \\
\hline Hollow MN I & $10 \mu g$ of pOVA in PBS, pH 7.4 & Hollow MN \\
\hline Hollow MN 2 & PEI:I0 $\mu g$ of pOVA (I:I) in PBS, pH 7.4 & Hollow MN \\
\hline Hollow MN 3 & Lipofectamine 2000: I0 $\mu$ g of pOVA (2:I) in PBS, pH 7.4 & Hollow MN \\
\hline Hollow MN 4 & Superfect: I0 $\mu \mathrm{g}$ of pOVA (6:I) in PBS, pH 7.4 & Hollow MN \\
\hline
\end{tabular}

Abbreviations: pOVA, plasmid DNA encoding ovalbumin; SC, subcutaneous; MN, microneedle; PBS, phosphate-buffered saline; PEI, polyethylenimine. 
6 times with T20/PBS and incubated with goat anti-mouse IgG HRP conjugate diluted to 1:4,000 for $45 \mathrm{~min}$. After washing, bound antibody was detected using a TMB, and $100 \mu \mathrm{L} /$ well of $1 \mathrm{~N} \mathrm{H}_{2} \mathrm{SO}_{4}$ was added to stop the reaction. The signal was quantified at $450 \mathrm{~nm}$ using a microplate reader (Universal Microplate Analyzer, Model AOPUS01 and AI53601; Packard BioScience).

\section{Statistical analysis}

Every assay was measured using at least 3 replicate samples. The data were expressed in the form of the mean and standard deviation (mean $\pm \mathrm{SD}$ ). All data were statistically analyzed by one-way analysis of variance (ANOVA). In all cases, a $P$-value of $<0.05$ was considered statistically significant.

\section{Results and discussion $\mathrm{MN}$ and EP patches and hollow MN characterization}

The morphology of MN and EP devices used in these studies was evaluated. The MN patches were $\sim 900 \mu \mathrm{m}$ in length and were arranged in 5 rows (Figure 2A). The blunted EP patches are shown in Figure 2B. The hollow MNs with a triangular silicone sheet were $\sim 300 \mu \mathrm{m}$ of insertion depth into the skin layer (Figure 2C). In the previous study, we evaluated the surface of the MN-treated skin to ensure that the MN array can effectively breach the skin and create a hole. ${ }^{29}$

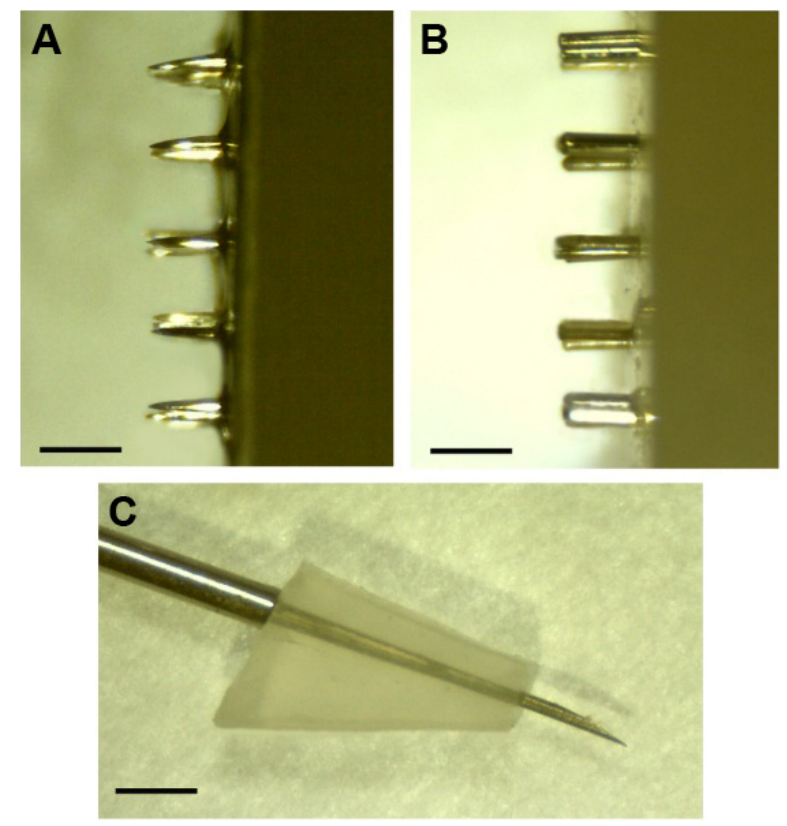

Figure 2 Photographs $(0.5 \times)$ of $(\mathbf{A}) \mathrm{MN}$ patch or $\mathrm{MN}+\mathrm{EP}$ patch, each with a height of $\sim 900 \mu \mathrm{m}$, (B) EP patch, each with a blunted array as an electrode, and (C) hollow MNs (bar $=1 \mathrm{~mm}$ ).

Abbreviations: $\mathrm{MN}$, microneedle; EP, electroporation.

\section{Characterization of cationic nanocarrier:pOVA complexes}

The particle size and zeta potential were plotted against the weight ratios of the different cationic nanocarrier:pOVA complexes (Figure 3). The PEI:pOVA complexes were performed at weight ratios of $0.25,0.5,1,2$, and 3 . As shown in Figure 3A, the size of the PEI:pOVA complexes was dependent on the concentration of PEI used. The smallest particle size of the PEI:pOVA complexes was observed at a weight ratio of 1 . Then, the particle sizes dramatically increased when the weight ratio increased from 2 to 3 . Increasing the weight ratio of PEI resulted in higher positive charges, and the surface of complexes was positive at a weight ratio of $0.5-3$ (Figure $3 \mathrm{~A}$ ). Because the weight ratio of the Lipofectamine 2000:pOVA complexes increased from 1 to 5 , the particle size of the complexes increased from 300 to $600 \mathrm{~nm}$, and the zeta potential of the complexes also increased from -10 to $60 \mathrm{mV}$. The positive charge of the complexes was observed at the weight ratio of 2-5 (Figure 3B). In addition, increasing the concentrations of Superfect from 2 to 15 resulted in larger complexes between 180 and $890 \mathrm{~nm}$, and the zeta potential of the complexes increased from 25 to $55 \mathrm{mV}$, as shown in Figure 3C. Although, the size of the Superfect:pOVA complexes was in the nanoscale range, there were very large sizes due to the dendrimer structure (hyperbranched macromolecules) or "tree-like" structure of Superfect. ${ }^{35}$

The zeta potential of the cationic nanocarrier:pOVA complexes is one of the important factors for DNA transfection because the zeta potential controls their DNA binding ability and the interaction between positive charges of the complexes and negative charges of the cell membranes. Therefore, to confirm the positive charge of the complexes, the complete complex formation was determined by agarose gel retardation (Figure 4). The result showed the complete complex formation of the PEI:pOVA complexes at the weight ratio of 1-3 (Figure 4A), the Lipofectamine 2000:pOVA complexes at a weight ratio of 2-5 (Figure 4B), and the Superfect:pOVA complexes at a weight ratio of 2-15 (Figure 4C). As a result, these weight ratios of the different nanocarrier complexes show that the particle size was in the nanoscale range with a highly positive charge. The correlation of the charge and the weight ratios demonstrated that the cationic nanocarriers were able to bind and neutralize the negative charge of pOVA. Therefore, it can be assumed that the optimal weight ratio of the PEI:pOVA complexes was between 1 and 3, the Lipofectamine 2000:pOVA complexes at a weight ratio of 2-5, and the Superfect:pOVA 


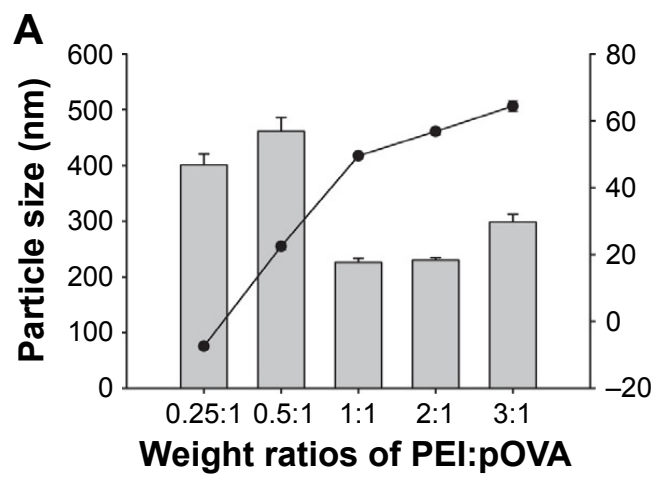

Weight ratios of PEI:pOVA
B

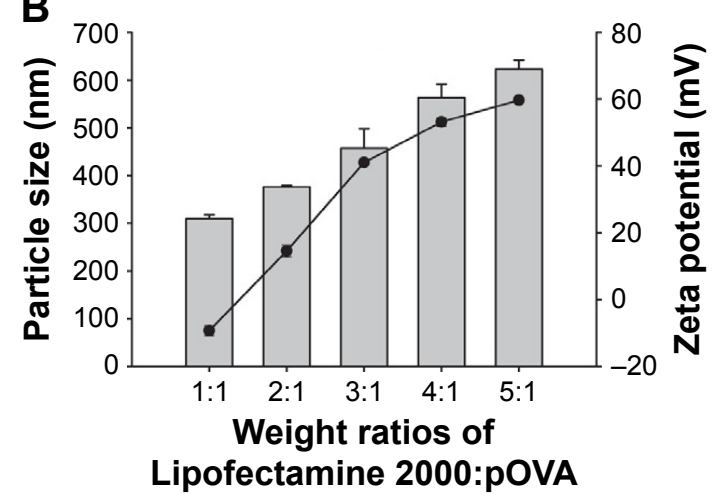

C

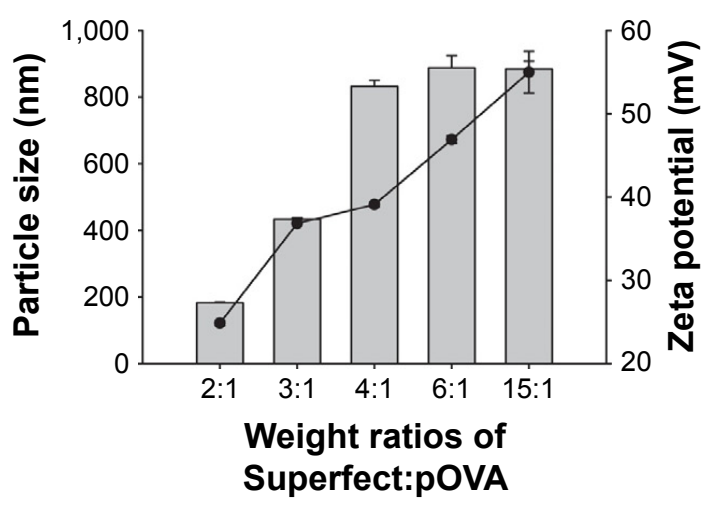

$\square$ Particle size $\rightarrow$ Zeta potential

Figure 3 The particle size and zeta potential for varying weight ratios of (A) PEl:pOVA complexes, (B) Lipofectamine 2000:pOVA complexes, and (C) Superfect:pOVA complexes.

Abbreviations: PEI, polyethylenimine; POVA, plasmid DNA encoding ovalbumin.

complexes at a weight ratio of $2-15$. However, the best weight ratio must be chosen in the next study to yield the highest transfection efficiency for further study.

\section{In vitro transfection efficiency}

An effective gene delivery system should provide high transfection efficiency. Therefore, we first tested the delivery of the pOVA-expressing ovalbumin protein. To evaluate the in vitro transfection efficiency, the complexes with different nanocarriers at various weight ratios were transfected into HeLa cells. It was found that the transfection efficiency of the complexes at all the weight ratios was significantly higher than naked pOVA transfection. The highest transfection efficiency of PEI, Lipofectamine 2000, and Superfect

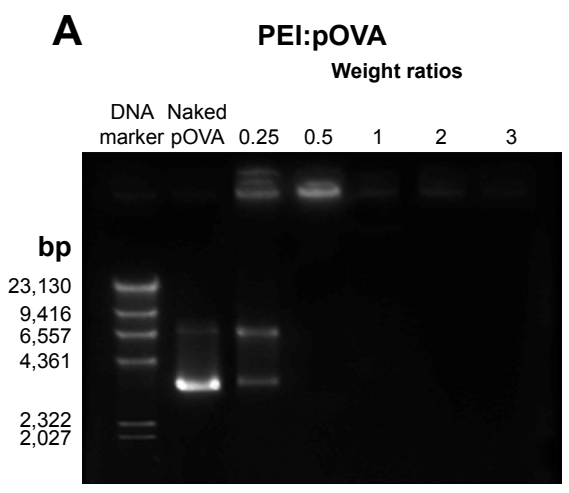

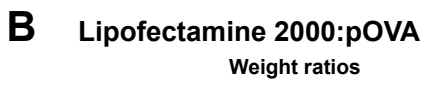

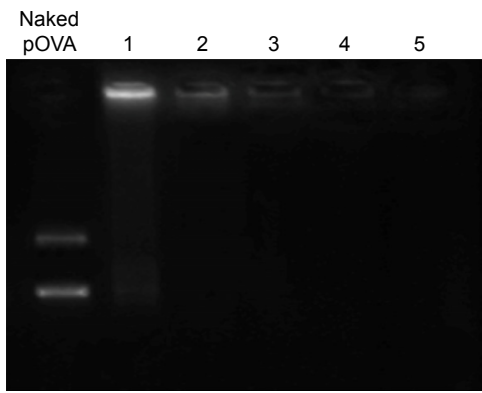

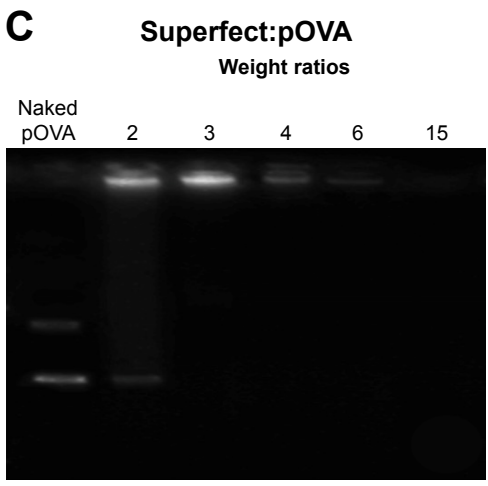

Figure 4 Gel retardation of (A) PEl:pOVA complexes, (B) Lipofectamine 2000:pOVA complexes, and (C) Superfect:pOVA complexes to confirm the positive charges of the complexes at different weight ratios.

Abbreviations: PEI, polyethylenimine; pOVA, plasmid DNA encoding ovalbumin. 
were observed for weight ratios of 1,2 , and 6 , respectively (Figure 5). In comparison, the transfection efficiency decreased as follows: PEI $(850 \pm 433 \mathrm{ng} / \mathrm{mL})>$ Lipofectamine $2000(354 \pm 172 \mathrm{ng} / \mathrm{mL})>$ Superfect $(43 \pm 9 \mathrm{ng} / \mathrm{mL})$. In the case of PEI, the highest transfection efficiency was obtained for a weight ratio of 1 , while the transfection efficiency showed very low ovalbumin protein expression for increased PEI:pOVA weight ratios (Figure 5A). These results suggested that the decreasing transfection efficiency may be due to the toxicity of high amounts of PEI. In addition, the results indicated that Superfect has the lowest transfection efficiency, which may be due to the large size of Superfect:pOVA compared with PEI:pOVA and Lipofectamine 2000:pOVA, as described earlier. To provide a high transfection efficiency, the size of the complexes should be $\sim 200 \mathrm{~nm}$, which may have restricted their ability to enter cells via receptor-mediated endocytosis. ${ }^{36,37}$ As a result, the PEI:pOVA complexes at a weight ratio of 1 , the Lipofectamine 2000:pOVA complexes at a weight ratio of 2 , and the Superfect:pOVA complexes at a weight ratio of 6 were selected to study the effect of different cationic nanocarriers using the best device (as evaluated in the following study), the hollow MNs, in an in vitro skin permeation study, and in vivo immunization study in mice.

\section{Effect of cationic nanocarrier:pOVA complexes on cytotoxicity}

Apart from the efficiency of nanocarriers for delivering DNA, cytotoxicity was also an important factor for DNA delivery. To assure the safety of the nanocarriers, an MTT assay was investigated in HeLa cell culture (Figure 6). The cell viability of the nanocarrier:pOVA complex-treated cells was compared with the untreated cells. Safe formulations should exhibit cell viabilities similar to those of untreated cells. As shown in Figure 6A, the viability of the cells transfected with PEI:pOVA complexes was observed to be concentrationdependent. The cell viability significantly decreased when transfecting with lower $(0.25: 1)$ and higher weight ratios of complexes (2:1 and 3:1). The cell viabilities of PEI:pOVA complexes at the weight ratios of $3: 1$ were $<80 \%$. Corresponding to transfection efficiencies, the transfection efficiency of PEI:pOVA complexes decreased at high weight
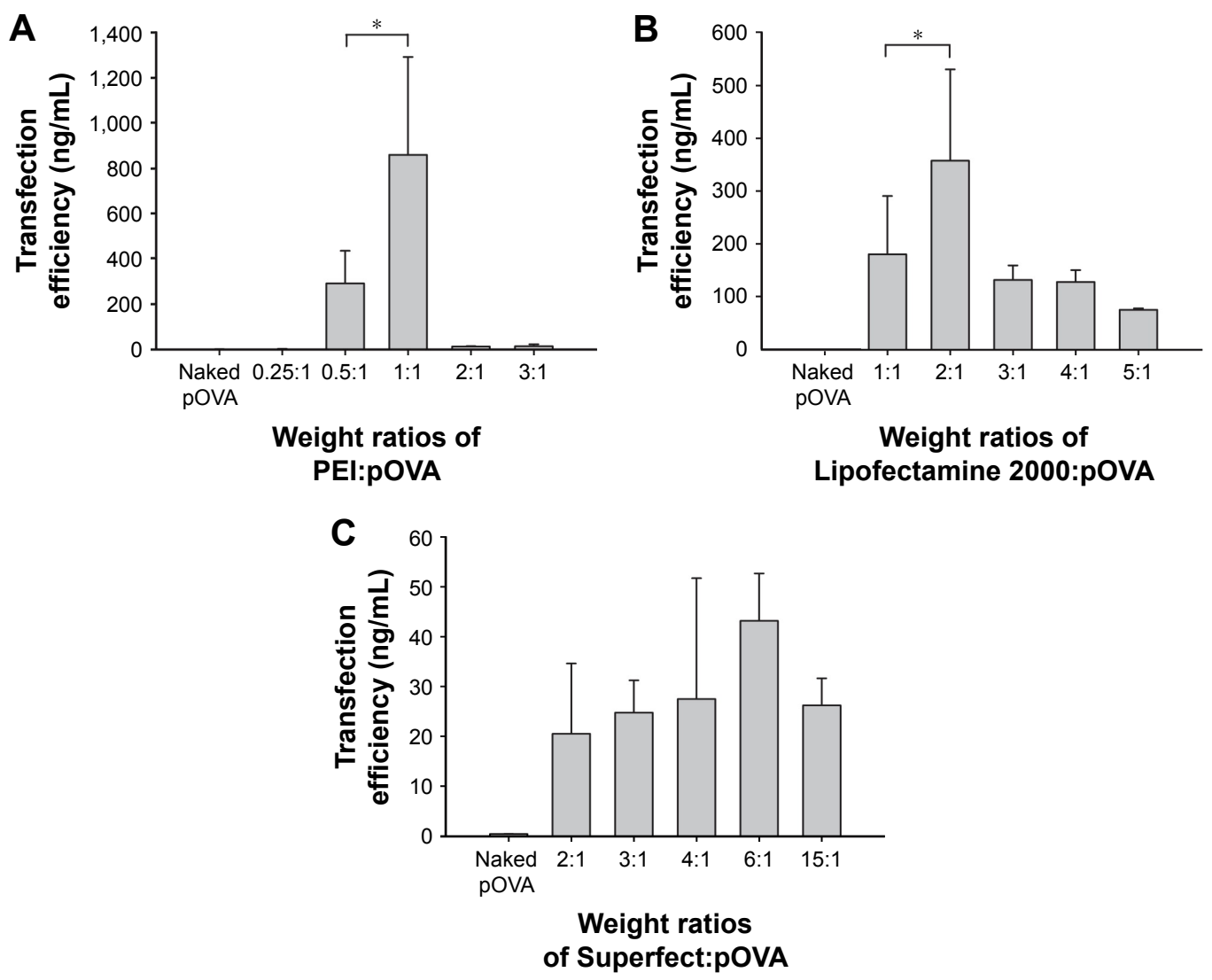

Figure 5 In vitro transfection efficiency in HeLa cells at varying weight ratios of (A) PEl:pOVA complexes, (B) Lipofectamine 2000:pOVA complexes, and (C) Superfect: pOVA complexes.

Note: ${ }^{*} P<0.05$ compared between two 2 groups.

Abbreviations: PEl, polyethylenimine; pOVA, plasmid DNA encoding ovalbumin. 

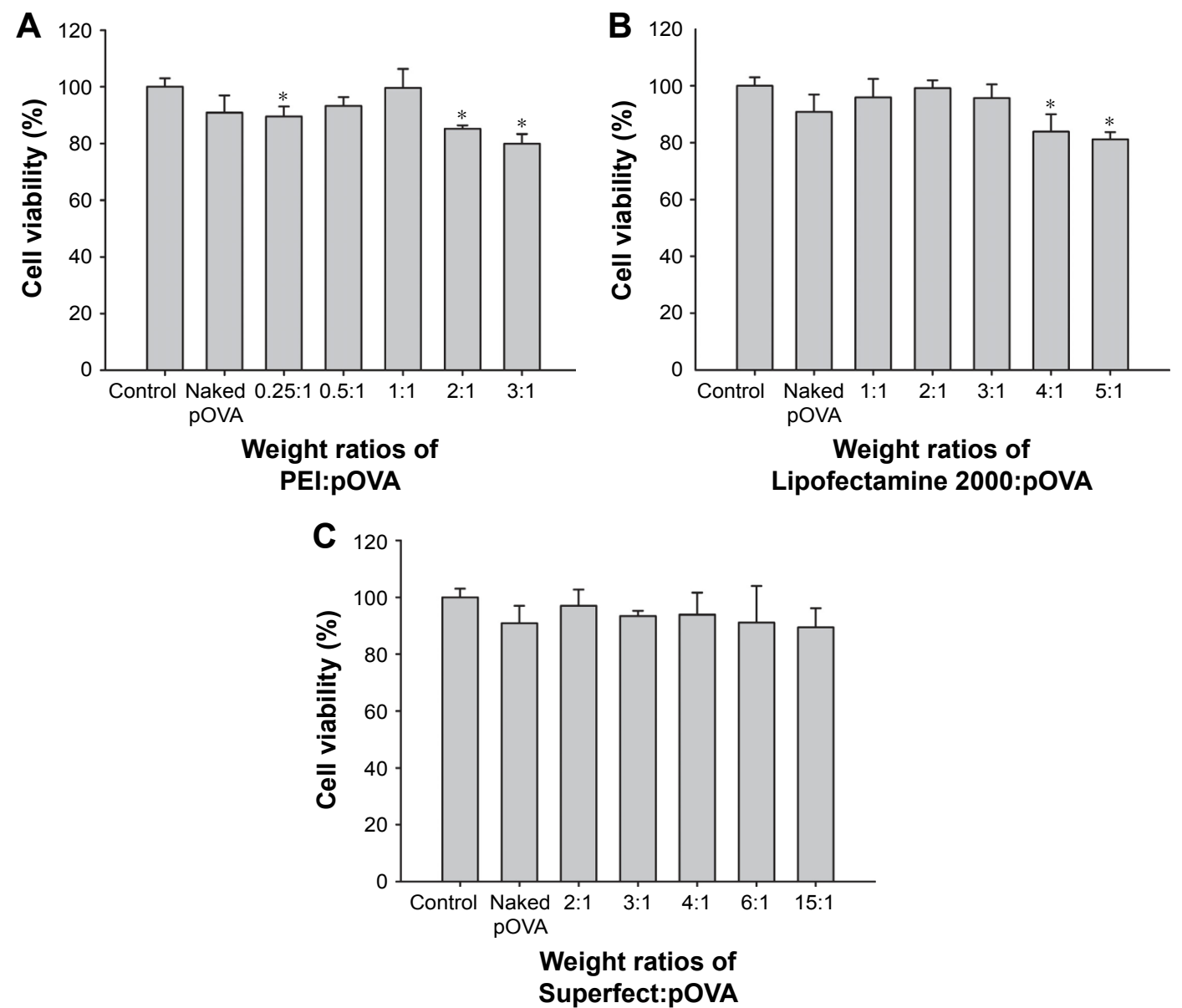

Figure 6 Cell viability of HeLa cells after transfected with (A) PEl:pOVA complexes, (B) Lipofectamine 2000:pOVA complexes, and (C) Superfect:pOVA complexes at pH 7.4. Notes: Each value was presented as mean \pm SD of triplicate samples. $* P<0.05$ compared to control.

Abbreviations: PEl, polyethylenimine; POVA, plasmid DNA encoding ovalbumin.

ratio due to the increase in cytotoxicity of the complexes. In addition, the cell viability of Lipofectamine 2000:pOVA complexes significantly decreased when the weight ratios of Lipofectamine 2000 were increased (4:1 and 5:1) as shown in Figure 6B. In case of Superfect:pOVA complexes, there were no significant differences between cell viabilities at any weight ratios compared with control (Figure 6C). As a result, PEI:pOVA complexes were safe for use at the weight ratios of 0.5:1 and 1:1, whereas Lipofectamine 2000:pOVA complexes were safe at the weight ratios of $1: 1,2: 1$, and $3: 1$.

\section{Serum stability of pOVA in the cationic nanocarrier:pOVA complexes}

The degradation of DNA by serum has been reported, and cationic nanocarriers have been used to protect DNA from nuclease degradation. ${ }^{30,38}$ Therefore, the stability of pOVA alone and different nanocarrier:pOVA complexes in the presence of $10 \%$ serum of BALB/c mice was evaluated. As shown in Figure 7, the DNA bands of the PEI:pOVA and Superfect:pOVA complexes in the presence of $10 \%$ serum were slightly faded; this may be because the nanocarriers can protect the pOVA from degradation by nuclease. However, the naked pOVA and Lipofectamine 2000:pOVA complexes in the presence of $10 \%$ serum were almost completely disappeared. This result suggested that the serum composition may interfere the property of Lipofectamine 2000:pOVA complexes. ${ }^{39}$

\section{In vitro skin permeation studies}

\section{Skin permeation of different delivery devices}

The skin samples used in this study were intact. The in vitro skin permeation profiles of pOVA without nanocarriers using the different delivery devices are illustrated in Figure 8A and $\mathrm{C}$. The most enhanced effect on the skin permeation of pOVA was found for use of the hollow MNs, followed by $\mathrm{MN}+\mathrm{EP}$ patch, the MN patch, and the EP patch. The cumulative amounts of pOVA permeated through the skin over $24 \mathrm{~h}$ after using the EP patch, the MN patch, the MN+EP patch, and hollow MNs were 10-, 25-, 36-, and 64-fold greater than that of untreated skin (passive diffusion), respectively. 


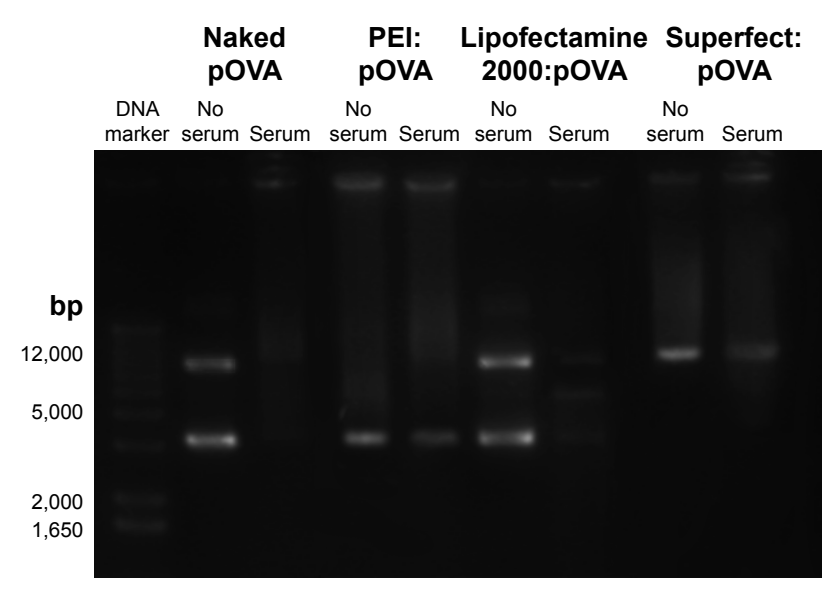

Figure 7 Gel retardation assay

Notes: Lane I, DNA marker; lane 2, naked pOVA without serum; lane 3, naked POVA in the presence of $10 \%$ serum of BALB/c mice for $6 \mathrm{~h}$; lane 4, PEl:pOVA complexes (I:I) without serum; lane 5, PEl:pOVA complexes (I:I) in the presence of 10\% serum; lane 6, Lipofectamine 2000:pOVA complexes (2:1) without serum; lane 7, Lipofectamine 2000:pOVA complexes $(2: 1)$ in the presence of $10 \%$ serum; lane 8, Superfect:pOVA complexes (6:1) without serum; and lane 9, Superfect: pOVA complexes $(6: 1)$ in the presence of $10 \%$ serum.

Abbreviations: pOVA, plasmid DNA encoding ovalbumin; PEI, polyethylenimine.
The cumulative amount of pOVA in the treated skin using the $\mathrm{MN}+\mathrm{EP}$ patch was 3-fold higher than EP patch-treated skin and 1.5-fold higher than $\mathrm{MN}$ patch-treated skin. These results suggest that the combined MN and EP patch had a synergistic effect for the transdermal delivery of pOVA because MNs and EPs exhibit different mechanisms of action for enhancing skin permeation. The combination of both methods can enhance the skin permeation of pOVA by first breaking the stratum corneum barrier due to use of the $\mathrm{MN}$ patch to create large microchannels. Then, an electric current stimulates aqueous pore formation by rearranging the lipid bilayer in the cell membranes resulting in a temporary increase in porosity and prolonging the duration of pore opening. ${ }^{29}$ Moreover, it can provide a local driving force for pOVA through the pores. ${ }^{27,28}$ Therefore, the combination of MNs and EPs was more effective than using each device alone. These results were consistent with the findings of previous studies by Yan et $\mathrm{al}^{28}$ and Petchsangsai et $\mathrm{al},{ }^{29}$ which indicated that the
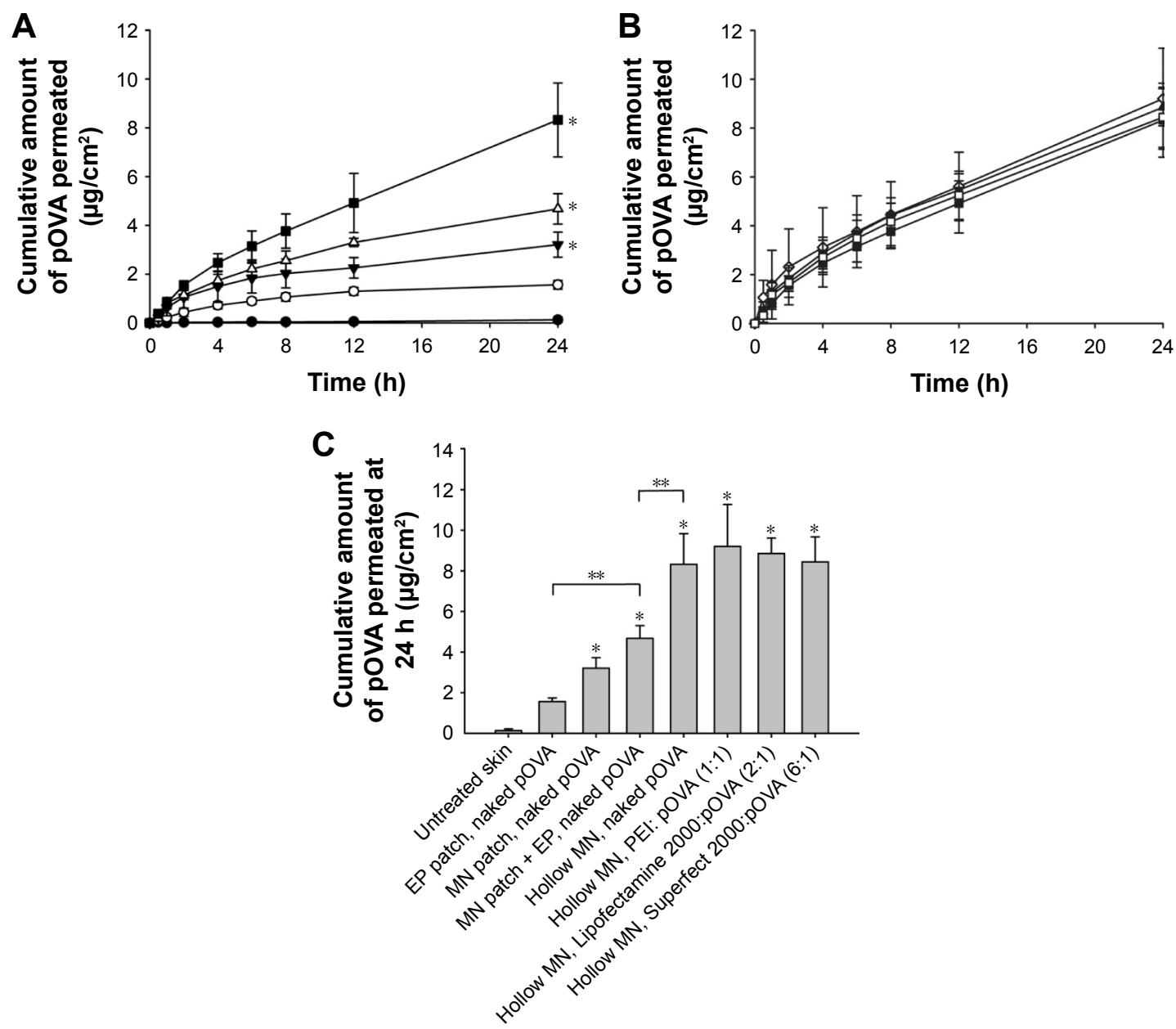

Figure 8 In vitro permeation profiles of pOVA across the skin with $(\mathbf{A})$ various delivery devices: $(\bullet)$ untreated skin, $(O)$ EP patch, $(\boldsymbol{\nabla})$ solid $M N$ patch, $(\triangle)$ combined solid MN and EP patch, $(\boldsymbol{\square})$ hollow MN, (B) hollow MN: $(\boldsymbol{\square})$ naked pOVA, different cationic nanocarriers, including $(\diamond)$ PEl:pOVA complexes, $(\mathbf{\Delta})$ Lipofectamine 2000:pOVA complexes and $(\square)$ Superfect:pOVA complexes, $(\mathbf{C})$ the cumulative amount at $24 \mathrm{~h}$ of all groups.

Notes: $* P<0.05$ compared to untreated skin. $* * P<0.05$ compared between 2 groups.

Abbreviations: pOVA, plasmid DNA encoding ovalbumin; EP, electroporation; MN, microneedle; PEl, polyethylenimine. 
combined devices significantly enhanced the skin permeation of macromolecules compared with individual methods.

In addition, the cumulative amount of pOVA using the hollow MNs was 2.6-fold and 2-fold higher than that of the $\mathrm{MN}$ patch alone and the MN+EP patch, respectively. The mechanism of hollow MNs depends on the "poke and flow" approach $;{ }^{21}$ similar to conventional injection, it can improve the transdermal delivery of pOVA by providing the pressure to push the pOVA solution into the skin. Moreover, an important advantage of hollow MNs over MN patches is the possibility to facilitate force-driven fluid flow, thereby allowing faster rates of drug delivery. ${ }^{21,40-42}$ Compared to $\mathrm{MN}+\mathrm{EP}$ patches, the hollow MNs had a significantly superior enhancing effect. Therefore, hollow MNs were chosen to study the effect of various types of nanocarriers on in vitro skin permeation, as they showed a superior enhancing effect.

\section{Skin permeation of POVA with cationic nanocarriers}

The effects of nanocarriers, including PEI, Lipofectamine 2000 , and Superfect complexed with pOVA $(50 \mu \mathrm{g})$, on skin permeation using the hollow MN device were investigated. Although the nanocarrier:pOVA complexes slightly improved skin permeation in comparison with pOVA without a nanocarrier, there were no significant differences between the cumulative amounts at $24 \mathrm{~h}$ (Figure $8 \mathrm{~B}$ and C). Although the size of the PEI:pOVA complexes at the weight ratio of 1:1 was the smallest $(230 \pm 7 \mathrm{~nm})$, followed by Lipofectamine

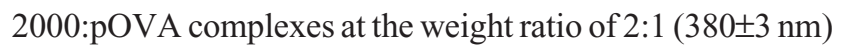
and the Superfect:pOVA complexes at the weight ratio of $6: 1(890 \pm 37 \mathrm{~nm})$, respectively, all of the complexes could pass through the skin into the receiver solution in similar amount. These might be because the pOVA had already been in the dermis by using hollow MNs; therefore, there was no significant effect of the size of the complexes on the skin permeability.

\section{In vivo immunization study}

To confirm the effect of nanocarriers on improving skin immunization, IgG antibody responses were investigated in mice after a second immunization with different pOVA formulations and routes (Table 1) by measuring the plasma concentration of OVA-specific antibodies. The results revealed that the levels of $\operatorname{IgG}$ in the mice immunized via a hollow $\mathrm{MN}$ were significantly higher than the levels for the $\mathrm{SC}$ immunization, as shown in Figure 9. The highest $\operatorname{IgG}$ responses were observed in the PEI:pOVA complexes followed by the Superfect:pOVA complexes, the Lipofectamine 2000:pOVA complexes, and naked pOVA, respectively.

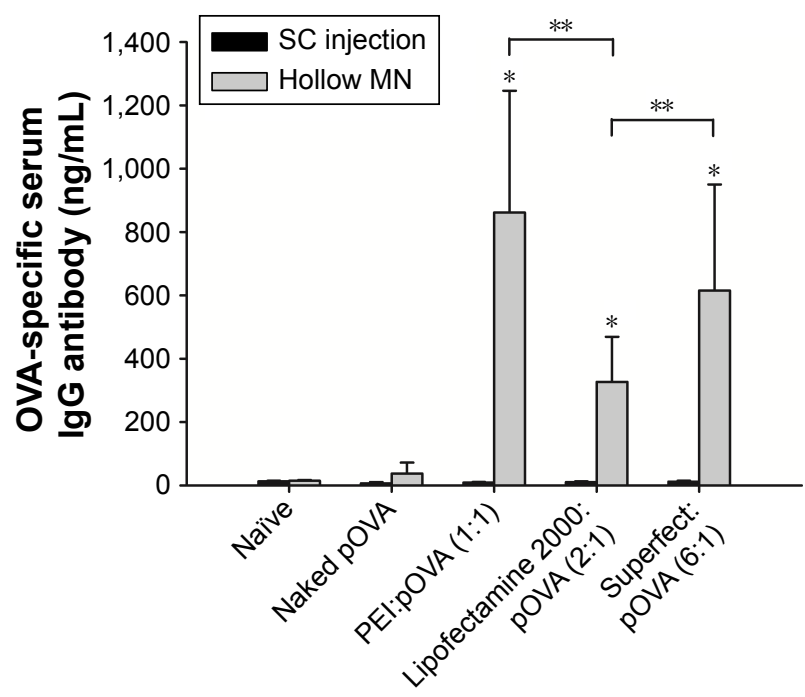

Figure 9 Antibody titers of serum IgG obtained from mice 21 days after vaccination with pOVA by $(\square)$ a hollow MN or $(\square)$ an SC injection $(n=6)$.

Notes: $* P<0.05$ compared to naïve group. $* * P<0.05$ compared between 2 groups. Abbreviations: IgG, immunoglobulin G; pOVA, plasmid DNA encoding ovalbumin; SC, subcutaneous; MN, microneedle; OVA, egg albumin; PEI, polyethylenimine.

Compared to naked pOVA, cationic nanocarrier:pOVA complexes significantly increased the immune responses. Upon injection of naked DNA to activate protein expression in vivo, it was found that within 90 min of injection, $99 \%$ of the injected naked DNA was degraded by endonuclease in the skin. ${ }^{43}$ As a result, naked DNA may be rapidly degraded by endonuclease in the skin before transcription and translation to induce protein expression in the cells. The IgG levels in the PEI:pOVA complexes were 2.6 and 1.4 times significantly higher than the Lipofectamine 2000:pOVA complexes and Superfect:pOVA complexes, respectively. In case of PEI, PEI with a high molecular weight (branched PEI, $25 \mathrm{kDa}$ ) was used in this study, as it exhibited high transfection efficiency due to efficient endosomal escape. ${ }^{44}$ It had a ratio of primary to secondary to tertiary amines of $1: 2: 1$, which it could be protonated in a physical environment. PEI has a strong buffering effect over a wide physiological $\mathrm{pH}$ range (the proton sponge effect) because PEI escapes from the endosome and facilitates the intracellular trafficking of pDNA ${ }^{45}$ In contrast with Lipofectamine 2000:pOVA complexes, the results showed the lowest level of IgG responses, which were likely due to the major disadvantages of cationic lipids in in vivo use. This result corresponds to the finding from the serum stability study, Lipofectamine 2000:pOVA complexes were degraded in the presence of $10 \% \mathrm{BALB} / \mathrm{c}$ mice serum. The lipoplexes were unstable upon aggregation in the in vivo environment, especially in serum-containing environment due to the destabilization of vesicles, resulting in pDNA leakage from the carriers before reaching the target cells. ${ }^{28}$ In the case 
of dendrimers, although the in vitro transfection efficiency of Superfect at $24 \mathrm{~h}$ corresponded to the lowest level, there was a higher IgG level than Lipofectamine 2000. Pojo et al $^{46}$ found that $48 \mathrm{~h}$ of exposure of the cell line dendrimers corresponded to $\sim 100 \%$ internalization efficiency of the tested concentrations. Moreover, the accumulation of radiolabeled dendrimers in mice was evaluated by Roberts et al, ${ }^{47}$ and dendrimers accumulated in several organs over $48 \mathrm{~h}$. These findings suggest that accumulation might occur because the expression process of dendrimer complexes did not complete within $24 \mathrm{~h}$, and thus, transfection durations $>24 \mathrm{~h}$ may be required. As a result, superior immune responses were clearly observed using PEI. In addition to the method of antigen administration, the type of nanocarrier is also an important factor for the effective induction of immune responses.

Regarding the safety of this vaccination method, no skin infection or pinpoint bleeding at the site of injection was observed in any of the mice. According to many publications, there have been no reports on skin infection due to the use of $\mathrm{MNs}^{15}$ because the skin has defense mechanisms to protect itself from pathogens. ${ }^{6}$ Generally, MNs with lengths $<1 \mathrm{~mm}$ do not cause bleeding. ${ }^{31,48}$ These results showed that using hollow MNs could induce a stronger immune response than $\mathrm{SC}$ injections of pOVA, which revealed that the skin is a very suitable target site for immunization.

\section{Conclusion}

The purpose of the present study was to ascertain the effectiveness of hollow MNs combined with nanocarriers for skin immunization with pOVA. We observed that the skin permeation and immune responses to pOVA relied on the type of $\mathrm{MN}$ and nanocarrier. Immunization of the skin with hollow MNs combined with PEI:pOVA complexes successfully enhanced skin permeation and induced the strongest IgG immune responses. Skin immunization with naked pOVA induced very low levels of IgG level. Immunization of mice with nanocarrier:pOVA complexes using the hollow MNs elicited significantly higher levels of serum IgG antibody responses compared to SC immunization, and no skin infection or pinpoint bleeding was observed. These immunological advantages, combined with safety benefits, revealed that hollow MN delivery of pOVA to the skin may offer an alternative method of skin immunization in the future.

\section{Acknowledgments}

The authors gratefully acknowledge the Thailand Research Funds through co-funding with the Golden Jubilee PhD Program (Grant number: PHD/0232/2558) and the National Vaccine
Institute, and Office of the Higher Education Commission (Grant No OHEC 59/01/03, NMR 2559A11462005), Silpakorn University Research and Development Institute for financial support. We wish to thank Professor Dr Kenji Sugibayashi (Faculty of Pharmaceutical Sciences, Josai University) for providing the hollow microneedles. We also thank Dr Chutinun Prasitpuriprecha (Faculty of Pharmacy, Ubon Ratchathani University) for providing the protocol for the immunization study.

\section{Disclosure}

The authors report no conflicts of interest in this work.

\section{References}

1. Kutzler MA, Weiner DB. DNA vaccines: ready for prime time? Nat Rev Genet. 2008;9(10):776-788.

2. Shedlock DJ, Weiner DB. DNA vaccination: antigen presentation and the induction of immunity. J Leukoc Biol. 2000;68(6):793-806.

3. Donnelly J, Berry K, Ulmer JB. Technical and regulatory hurdles for DNA vaccines. Int J Parasitol. 2003;33(5-6):457-467.

4. van Drunen Littel-van den Hurk S, Babiuk SL, Babiuk LA. Strategies for improved formulation and delivery of DNA vaccines to veterinary target species. Immunol Rev. 2004;199:113-125.

5. Liu MA. DNA vaccines: an historical perspective and view to the future. Immunol Rev. 2011;239(1):62-84.

6. Kupper TS, Fuhlbrigge RC. Immune surveillance in the skin: mechanisms and clinical consequences. Nat Rev Immunol. 2004;4(3):211-222.

7. Nagao K, Ginhoux F, Leitner WW, et al. Murine epidermal Langerhans cells and langerin-expressing dermal dendritic cells are unrelated and exhibit distinct functions. Proc Natl Acad Sci U S A. 2009;106(9): 3312-3317.

8. Jepps OG, Dancik Y, Anissimov YG, Roberts MS. Modeling the human skin barrier - towards a better understanding of dermal absorption. Adv Drug Deliv Rev. 2013;65(2):152-168.

9. Kumar A, Wonganan P, Sandoval MA, Li X, Zhu S, Cui Z. Microneedlemediated transcutaneous immunization with plasmid DNA coated on cationic PLGA nanoparticles. J Control Release. 2012;163(2): 230-239.

10. Laddy DJ, Yan J, Khan AS, et al. Electroporation of synthetic DNA antigens offers protection in nonhuman primates challenged with highly pathogenic avian influenza virus. J Virol. 2009;83(9):4624-4630.

11. Hooper JW, Golden JW, Ferro AM, King AD. Smallpox DNA vaccine delivered by novel skin electroporation device protects mice against intranasal poxvirus challenge. Vaccine. 2007;25(10):1814-1823.

12. Yager EJ, Dean HJ, Fuller DH. Prospects for developing an effective particle-mediated DNA vaccine against influenza. Expert Rev Vaccines. 2009;8(9):1205-1220.

13. Haensler J, Verdelet C, Sanchez V, et al. Intradermal DNA immunization by using jet-injectors in mice and monkeys. Vaccine. 1999; 17(7-8):628-638.

14. Huang HN, Li TL, Chan YL, Chen CL, Wu CJ. Transdermal immunization with low-pressure-gene-gun mediated chitosan-based DNA vaccines against Japanese encephalitis virus. Biomaterials. 2009; 30(30):6017-6025.

15. Kim YC, Song JM, Lipatov AS, et al. Increased immunogenicity of avian influenza DNA vaccine delivered to the skin using a microneedle patch. Eur J Pharm Biopharm. 2012;81(2):239-247.

16. Mitragotri S. Current status and future prospects of needle-free liquid jet injectors. Nat Rev Drug Discov. 2006;5(7):543-548.

17. Henry S, McAllister DV, Allen MG, Prausnitz MR. Microfabricated microneedles: a novel approach to transdermal drug delivery. J Pharm Sci. 1998;87(8):922-925. 
18. van der Maaden K, Jiskoot W, Bouwstra J. Microneedle technologies for (trans)dermal drug and vaccine delivery. J Control Release. 2012; 161(2):645-655.

19. Zhang S, Qiu Y, Gao Y. Enhanced delivery of hydrophilic peptides in vitro by transdermal microneedle pretreatment. Acta Pharm Sin B. 2014;4(1):100-104

20. Santos S, Stefancich M, Hernandez H, Chiesa M, Thomson NH. Hydrophilicity of a single DNA molecule. JPhys Chem C. 2012;116(4): 2807-2818.

21. Prausnitz MR. Microneedles for transdermal drug delivery. Adv Drug Del Rev. 2004;56(5):581-587.

22. Tuan-Mahmood TM, McCrudden MT, Torrisi BM, et al. Microneedles for intradermal and transdermal drug delivery. Eur J Pharm Sci. 2013; 50(5):623-637.

23. Titomirov AV, Sukharev S, Kistanova E. In vivo electroporation and stable transformation of skin cells of newborn mice by plasmid DNA. Biochim Biophys Acta. 1991;1088(1):131-134.

24. Rosati M, Valentin A, Jalah R, et al. Increased immune responses in rhesus macaques by DNA vaccination combined with electroporation. Vaccine. 2008;26(40):5223-5229.

25. Hirao LA, Wu L, Khan AS, et al. Combined effects of IL-12 and electroporation enhances the potency of DNA vaccination in macaques. Vaccine. 2008;26(25):3112-3120.

26. Otten G, Schaefer M, Doe B, et al. Enhancement of DNA vaccine potency in rhesus macaques by electroporation. Vaccine. 2004;22(19): 2489-2493.

27. Denet AR, Vanbever R, Preat V. Skin electroporation for transdermal and topical delivery. Adv Drug Deliv Rev. 2004;56(5):659-674.

28. Yan K, Todo H, Sugibayashi K. Transdermal drug delivery by inskin electroporation using a microneedle array. Int J Pharm. 2010; 397(1-2):77-83.

29. Petchsangsai M, Rojanarata T, Opanasopit P, Ngawhirunpat T. The combination of microneedles with electroporation and sonophoresis to enhance hydrophilic macromolecule skin penetration. Biol Pharm Bull. 2014;37(8):1373-1382.

30. Niyomtham N, Apiratikul N, Suksen K, OpanasopitP, Yingyongnarongkul B-E. Synthesis and in vitro transfection efficiency of spermine-based cationic lipids with different central core structures and lipophilic tails. Bioorg Med Chem Lett. 2015;25(3):496-503.

31. OpanasopitP,LeksantikulL, Niyomtham N, Rojanarata T, Ngawhirunpat T, Yingyongnarongkul BE. Cationic niosomes an effective gene carrier composed of novel spermine-derivative cationic lipids: effect of central core structures. Pharm Dev Technol. Epub 2015 Dec 27:1-10.

32. Davies DJ, Ward RJ, Heylings JR. Multi-species assessment of electrical resistance as a skin integrity marker for in vitro percutaneous absorption studies. Toxicol In Vitro. 2004;18(3):351-358.
33. Pamornpathomkul B, Duangjit S, Laohapatarapant S, Rojanarata T, Opanasopit P, Ngawhirunpat T. Transdermal delivery of fluorescein isothiocyanate-dextrans using the combination of microneedles and lowfrequency sonophoresis. Asian J Pharm Sci. 2015;10(5):415-424.

34. Prausnitz MR, Mikszta JA, Cormier M, Andrianov AK. Microneedlebased vaccines. Curr Top Microbiol Immunol. 2009;333:369-393.

35. Sheikhi Mehrabadi F, Fischer W, Haag R. Dendritic and lipid-based carriers for gene/siRNA delivery (a review). Curr Opin Solid State Mater Sci. 2012;16(6):310-322.

36. Dincer S, Turk M, Piskin E. Intelligent polymers as nonviral vectors. Gene Ther. 2005;12(suppl 1):S139-S145.

37. Cooper MJ. Chapter 2 - noninfectious gene transfer and expression systems for cancer gene therapy A2. In: Lattime EC, Gerson SL, editors. Gene Therapy of Cancer (Second Edition). San Diego, CA: Academic Press; 2002:31-52.

38. Peng J, He X, Wang K, et al. An antisense oligonucleotide carrier based on amino silica nanoparticles for antisense inhibition of cancer cells. Nanomedicine. 2006;2(2):113-120.

39. HenggeUR, Dexling B, Udvardi A, Volc-PlatzerB, MirmohammdsadeghA. Safety and pharmacokinetics of naked plasmid DNA: studies on dissemination and ectopic expression. In: Hengge UR, Volc-Platzer B, editors. The Skin and Gene Therapy. Berlin, Heidelberg. Berlin, Heidelberg: Springer; 2001:67-80.

40. Bal SM, Ding Z, van Riet E, Jiskoot W, Bouwstra JA. Advances in transcutaneous vaccine delivery: do all ways lead to Rome? J Control Release. 2010;148(3):266-282.

41. Levin Y, Kochba E, Kenney R. Clinical evaluation of a novel microneedle device for intradermal delivery of an influenza vaccine: are all delivery methods the same? Vaccine. 2014;32(34):4249-4252.

42. Banga AK. Microporation applications for enhancing drug delivery. Expert Opin Drug Deliv. 2009;6(4):343-354.

43. Yang J, Liu H, Zhang X. Design, preparation and application of nucleic acid delivery carriers. Biotechnol Adv. 2014;32(4):804-817.

44. Amiji MM. Polymeric Gene Delivery: Principles and Applications. Boca Raton, FL: CRC Press; 2005.

45. Hahn P, Scanlan E. Gene delivery into mammalian cells: an overview on existing approaches employed in vitro and in vivo. Top Curr Chem. 2010;296:1-13.

46. Pojo M, Cerqueira SR, Mota T, et al. In vitro evaluation of the cytotoxicity and cellular uptake of CMCht/PAMAM dendrimer nanoparticles by glioblastoma cell models. J Nanopart Res. 2013;15(5):1621.

47. Roberts JC, Bhalgat MK, Zera RT. Preliminary biological evaluation of polyamidoamine (PAMAM) Starburst dendrimers. J Biomed Mater Res. 1996;30(1):53-65.

48. Gill HS, Denson DD, Burris BA, Prausnitz MR. Effect of microneedle design on pain in human subjects. Clin J Pain. 2008;24(7):585-594.
International Journal of Nanomedicine

\section{Publish your work in this journal}

The International Journal of Nanomedicine is an international, peerreviewed journal focusing on the application of nanotechnology in diagnostics, therapeutics, and drug delivery systems throughout the biomedical field. This journal is indexed on PubMed Central, MedLine, CAS, SciSearch ${ }^{\circledR}$, Current Contents ${ }^{\circledR} /$ Clinical Medicine,

\section{Dovepress}

Journal Citation Reports/Science Edition, EMBase, Scopus and the Elsevier Bibliographic databases. The manuscript management system is completely online and includes a very quick and fair peer-review system, which is all easy to use. Visit http://www.dovepress.com/ testimonials.php to read real quotes from published authors. 